DOI: $10.7242 / 2658-705 X / 2020.2 .1$

УДК 536.2.023

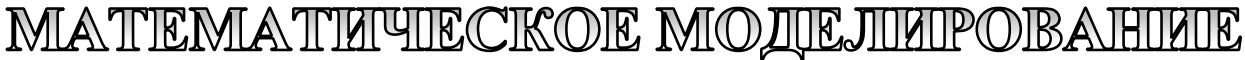

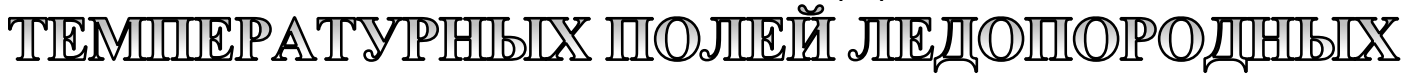

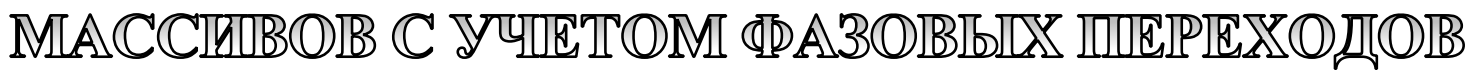

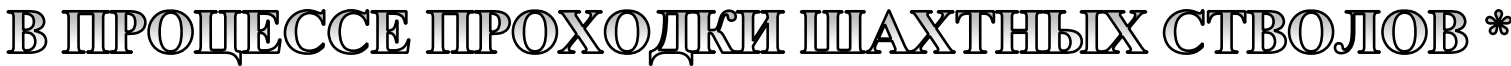

Р.Н. Сулейманов, Пермский национальный исследовательский политехнический университет А.А. Чекалкин, Пермский наииональный исследовательский политехнический университет

Объектом исследования является образование ледопородного массива при проходке шахтного ствола.

Цель работы - построение математической модели пространственных полей температур в породном массиве в процессе работы замораживающих скважин при проходке шахтного ствола.

Данная работа проводилась на базе Пермского национального исследовательского политехнического университета. Для предварительного определения времени образования ледопородного массива были использованы проектировочные расчеты, предоставленные заказчиком, и аналитическое решение уравнения нестационарной теплопроводности.

Для моделирования динамики температурного поля вокруг шахтного ствола в процессе заморозки был использован прикладной пакет «ANSYS», с помощью которого можно также определить время ледообразования в горном массиве. Исходная геометрическая и теплофизическая информация была подготовлена в геоинформационной системе «ArcGIS».

Получены зависимости толщины ледопородного массива от времени и начальной температуры среды. Определены приблизительные сроки образования ледопродного массива требуемой толщины, необходимого для проходки шахтного ствола, а также момент его смыкания.

Ключевые слова: ледопородный массив, теплопроводность, теплоемкость, скважина, шахтный ствол, математическое моделирование, нестационарная теплопроводность.

Верхнекамское месторождение калийных и магниевых солей расположено в центральной части Соликамской впадины Предуральского краевого прогиба $[9,10]$. Талицкий участок расположен в его юго- восточной части, в краевой зоне, на западном крыле Еловского поднятия (с осью, ориентированной на северо-восток), южная часть участка осложнена Талицким поднятием. Общий наклон запад-

* Статья подготовлена при финансовой поддержке гранта РФФИ № 16-41-590375p-a «Структурно-неоднородные модели тепло-массопереноса, деформирования и разрушения компонентов структуры искусственных геокомпозитов и пространственно неоднородных ледопородных массивов с учетом фазовых переходов». 
ного крыла Еловского поднятия незначительный, изменяется в пределах $1 \div 2^{\circ}$.

Участок строительства клетевого и скипового стволов Талицкого ГОК характеризуется сложной геологической структурой. На некоторых глубинах были отмечены водопритоки, скорость которых значительно превышает предельно допустимые. Для безопасной проходки был предложен метод замораживания. В связи с этим объектом научно-исследовательской работы является образование ледопородного массива в процессе проходки шахтных стволов.

Согласно проектной документации, предварительно к расчету принимается схема, при которой сечение ствола будет частично проморожено. Толщина ледопородного ограждения при частичном промораживании сечения ствола $\delta$ определяется следующим соотношением:

$$
\delta=k k_{H} \delta_{1},
$$

где $k$ - эмпирический коэффициент, $k=1,1$;

$k_{H}$-коэффициент надежности при данных условиях работы;

$\delta_{1}-$ толщина ледопородного ограждения при условии промораживания сечения ствола, 4,7 м.

Толщина ледопородного ограждения при частичном промораживании сечения ствола составит

$$
\delta=1,2 \cdot 1,1 \cdot 4,7=6,2 \text { м. }
$$

Предварительный расчет продолжительности активного замораживания пород выполняется по скорости нарастания ледопородного ограждения.

$$
T=0,5 \cdot \frac{\delta}{v}=0,5 \cdot \frac{6,2}{0,012}=285,3=260 \text { сут.; }
$$

$v$ - скорость нарастания ледопородного ограждения, м/сут.; в глинистых породах $v=0,01 \div 0,015$ м/сут.; принимаем $v=0,012 \mathrm{M} /$ сут.

Скорость определяется эмпирически, на основе анализа процесса замораживания горных пород на различных стволах, и приведена в справочной литературе [19]. Данный метод позволяет рассчитать толщину ледопородного массива и время замораживания грунта до определенных размеров, за счет эмпирических коэффициентов и коэффициентов надежности, в короткие сроки. Однако при этом, результат расчетов может значительно отличаться от реальных значений, что может повлечь за собой риск возникновения аварий, в противном случае, затраты на образование ледопородного массива будут неоправданно большими.

Для определения скорости замораживания, близкой к реальной, а также и энергии замораживания, необходимо учитывать реальную структуру горного массива на всей глубине шахтного ствола. C помощью аналитических решений задач нестационарной теплопроводности $[1-3,6,8,13,17,20,21,23]$ возможно определение времени сходимости ледопородного массива, т.е. времени образования замкнутого контура ледопородного массива вокруг шахтного ствола, и энергетических затрат, а также достижения им необходимой толщины. Также на основе численных методов расчета $[5,11,12,15]$ и математического моделирования с помощью метода конечных элементов $[4,16,18]$ можно с достаточной точностью описать процессы, происходящие в горном массиве.

Цель работы - анализ температурных полей ледопородного массива в процессе проходки шахтных стволов. Соответственно задача - математическое моделирование температурных полей ледопородного массива в процессе проходки шахтных стволов.

\section{Постановка задачи теплопроводности}

Дифференциальное уравнение теплопроводности для одномерной нестационарной задачи охлаждения бесконечного полого цилиндра без внутренних источников теплоты записывается в следующем виде:

$$
\frac{\partial t}{\partial \tau}=a\left(\frac{\partial^{2} t}{\partial \mathrm{r}^{2}}+\frac{1}{\mathrm{r}} \times \frac{\partial t}{\partial \mathrm{r}}\right),
$$

Где $t$ - температура по шкале Кельвина, С;

$\tau-$ время кристаллизации горного массива, с; 
$\mathrm{r}$ - расстояние от источника холода, м.

Физическое содержание этого уравнения можно выразить следующим образом: скорость увеличения температуры пропорциональна теплоподводу посредством теплопроводности.

Математическая постановка задачи:

$$
\left\{\begin{array}{l}
\frac{\partial t}{\partial \tau}=a\left(\frac{\partial^{2} t}{\partial \mathrm{r}^{2}}+\frac{1}{\mathrm{r}} \cdot \frac{\partial t}{\partial \mathrm{r}}\right), \mathrm{r} \in(0, l), \tau>0, \\
\left.t\right|_{\tau=0}=t_{\infty} \\
t\left(\mathrm{r}=\mathrm{r}_{0}, \tau\right)=t_{0} \\
t(\mathrm{r}=R, \tau)=t_{\infty}
\end{array}\right.
$$

Где $a$ - коэффициент температуропроводности, $\mathrm{m}^{2} / \mathrm{c}$;

$t_{0}$ - температура источника холода, $\mathrm{C}^{\circ}$;

$t_{\infty}$ - температура горного массива в начальный момент времени, $\mathrm{C}^{\circ}$.

Аналитические расчеты были проведены с помощью MAPLE, который позволяет решать системы дифференциальных и интегральных уравнений высших порядков. В результате решения была получено следующее выражение:

$$
t(x, \tau)=t_{\infty}+\left(t_{0}-t_{\infty}\right) \cdot \frac{E i\left(\frac{r^{2}}{4 a \tau}\right)}{E i(0,05)} .
$$

В результате использования экспериментальных данных в процессе решения получены графики изменения температур (t) в зависимости от времени (рис. 1) и расстояния от источника заморозки (r). B качестве примера применялись свойства Пестроцветной толщи (табл. 1).

Используя формулу (5), можно определить время, при котором горная порода замерзнет до температуры $0^{\circ} \mathrm{C}$ (температура замерзания пресной воды) и $-10^{\circ} \mathrm{C}$ (температура замерзания соленой воды) на расстоянии, равном половине толщины ледопородного массива, (3м.), оно равно 170 и 350 суток соответственно.

Таблииа 1

\section{Теплофизические свойства пестроцветной толщи}

\begin{tabular}{|c|c|c|c|c|}
\hline \multirow{2}{*}{$\begin{array}{c}\text { № } \\
\text { п/п }\end{array}$} & $\begin{array}{c}\text { Типы } \\
\text { грунтовых } \\
\text { толщ }\end{array}$ & \multicolumn{3}{|c|}{$\begin{array}{c}\text { Теплосиизические } \\
\text { параметры }\end{array}$} \\
\cline { 3 - 5 } & $\lambda, \mathrm{BT} /(\mathrm{M} \cdot 0 \mathrm{C})$ & $\begin{array}{c}\mathrm{C} \\
\text { Дж/(кг.0С })\end{array}$ & $\begin{array}{c}\rho, \\
\mathrm{\kappa} / \mathrm{M}^{3}\end{array}$ \\
\hline 1 & $\begin{array}{c}\text { Пестроцве- } \\
\text { тная Толща }\end{array}$ & 1,23 & 728 & 2300 \\
\hline
\end{tabular}

\section{Использование сеточных методов} для решения задач теплопроводности

В рамках работы по внедрению перспективных методик теплового проектирования технических систем использовался пакет системного анализа ANSYS. Основанием для этого послужили следующие преимущества пакета:

1. Высокая степень автоматизации выполнения дискретизации расчетной области, задания граничных условий. На рис. 2 изображена конечно-элементная сетка, созданная в ANSYS Workbench

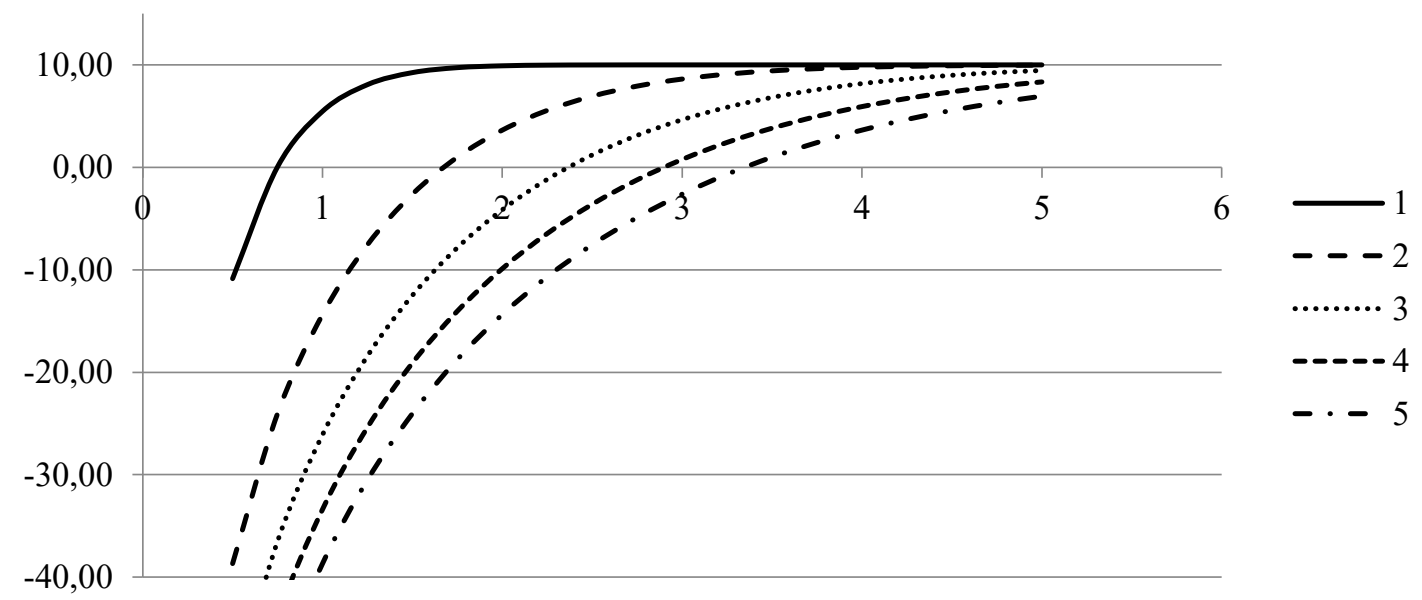

Рис. 1. Графики изменения температур при воздействии заморозки, зависящих от расстояния при фиксированном времени с шагом 50 суток: 1 - температурное поле через 10 суток после начала заморозки, 5 - после 210 суток замораживания 


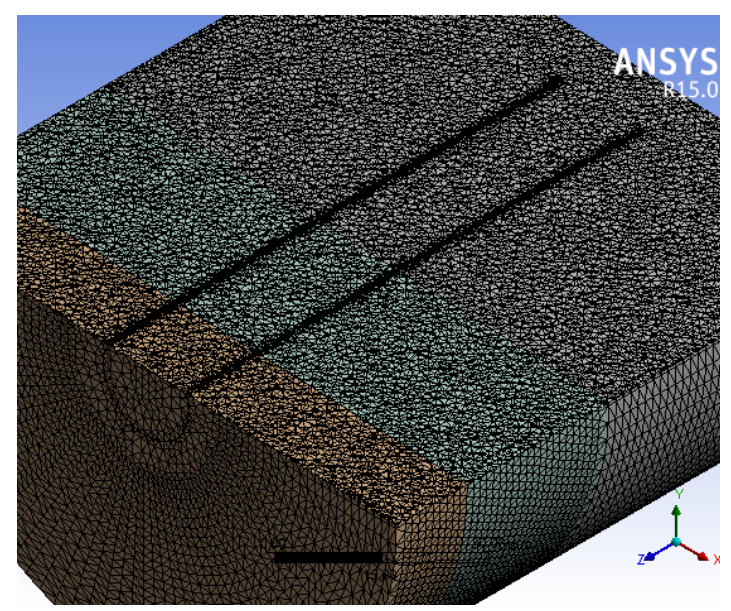

Рис. 2. Пространственная сеточная модель ледопородного массива с замораживающими скважинами: 4387224 узлов, 3107775 конечных элементов

для решения задачи нестационарной теплопроводности.

2. Наглядность геометрической модели изучаемого объекта, легкость в отслеживании свойств материалов, размеров его составных частей.

3. Возможность сочетать быстроту подготовки модели с наглядностью выполнения действий благодаря совместному использованию задания операций, как в командном режиме, так и в режиме графического интерфейса.

4. Широкий инструментарий алгоритмов решения, специальных опций, выбираемых в зависимости от типа задачи.

5. Богатые возможности анализа и обработки полученных результатов в режиме постпроцессора.

Возможность проводить оптимизацию конструкции по заданным значениям искомых величин.

Практическое использование ANSYS как инструмента для решения численных методов может быть реализовано на высокопроизводительных вычислительных машинах для обеспечения более точного и относительно быстрого получения требуемых результатов. В процесce выполнения научно-исследовательской работы были использованы ресурсы вычислительного кластера ПНИПУ.
Математическое моделирование

температурных полей в задаче формирования ледопородного массива

В ходе решения задачи была создана двумерная конечно-элементная модель с круглым отверстием $d=0,15$ м, теплофизические свойства которой: $\mathrm{C}=725$ Дж/(кг.С); $\lambda=0,5 \mathrm{BT} /(\mathrm{м} \cdot \mathrm{C}) ; \rho=2300 \mathrm{\kappa г} / \mathrm{m}^{3}$.

Двумерная конечно-элементная модель включает 43 расположенные по кругу отверстия, соответствующие системе замораживающих скважин, с аналогичными свойствами и краевыми условиями. Конечно-элементная сетка данной модели состоит из 55914 узлов и 18480 элементов.

Далее была создана пространственная модель слоистого цилиндрического тела (рис. 3), конечно-элементная сетка представлена на рис. 2, она состоит из 4387224 узлов и 3107775 третраэдральных элементов. В качестве условия контакта на границе раздела двух сред принималось равенство температуры. Цилиндрические отверстия были построены по координатам замораживающих скважин, пробуренных на Талицком участке Верхнекамского месторождения.

Проведено моделирование полей температур, показан процесс смыкания низкотемпературных областей соседних замораживающих скважин и формирование ледопородной защиты кольцевого типа для проведения работ по проходке ствола шахты.

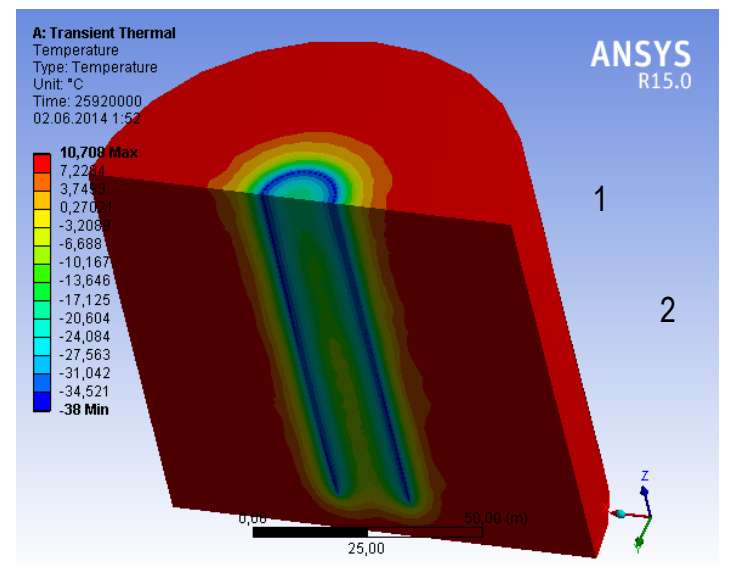

Рис. 3. Поле температуры при воздействии источников холода

в пространственно-неоднородном массиве: 1 - расположение замораживающих скважин; 2 - температурный фронт 
На рис. 3 и 4 изображены поля температур и изолинии в сечении горного массива. В качестве расчетной модели строение реального горного массива было упрощено, при проведении численного моделирования массив состоял из трех различных слоев, теплофизические свойства (табл. 2) которых были рассчитаны как среднеарифметические по глубине, влияние водопотоков на процессы теплообмена не учитывалось.

Исходная геометрическая и теплофизическая информация была подготовлена в геоинформационной системе «ArcGIS».

По инклинометрическим данным скважин создана модель двух шахтных стволов (рис. 5), в которой каждому слою горного массива были присвоены конкретные теплофизические свойства.

Геоинформационная система ArcGIS позволяет рассчитывать время образова-

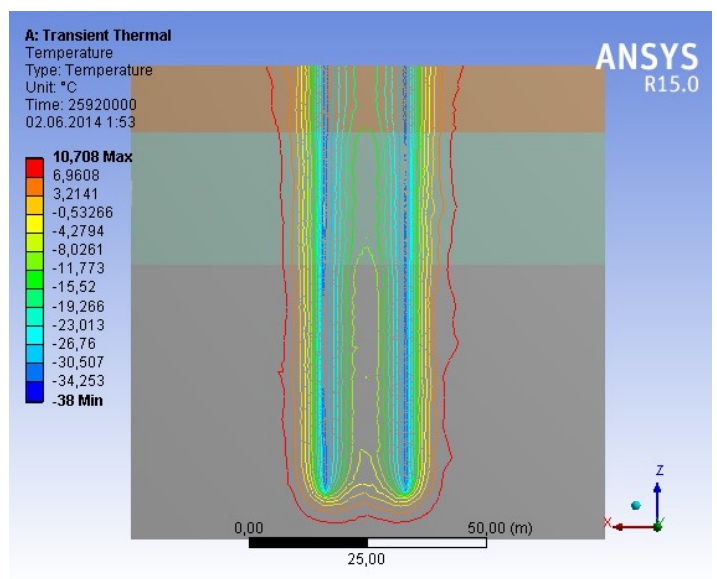

Рис. 4. Изолинии температур при воздействии источников холода в пространственно-неоднородном массиве

Таблицуа 2

Теплофизические свойства грунта по толщам горного массива

\begin{tabular}{|c|c|c|c|c|}
\hline \multirow[b]{2}{*}{$\begin{array}{l}\text { № } \\
\Pi / \Pi\end{array}$} & \multirow[b]{2}{*}{$\begin{array}{c}\text { Типы грунтовых } \\
\text { толщ }\end{array}$} & \multicolumn{3}{|c|}{ Теплофизические параметры } \\
\hline & & $\lambda, \mathrm{BT} /\left(\mathrm{M} \cdot{ }^{\circ} \mathrm{C}\right)$ & $\begin{array}{c}\mathrm{C}, \\
\text { Дж/(кг.0 }\end{array}$ & $\begin{array}{c}\rho, \\
\kappa \Gamma / M^{3}\end{array}$ \\
\hline 1 & $\begin{array}{c}\text { Пестроцветная } \\
\text { толща }\end{array}$ & 1,23 & 728 & \multirow{3}{*}{2300} \\
\hline 2 & $\begin{array}{c}\text { Терригенно- } \\
\text { карбонатная } \\
\text { толща }\end{array}$ & 0,89 & 654 & \\
\hline 3 & $\begin{array}{l}\text { Соляно- } \\
\text { мергельная } \\
\text { толща }\end{array}$ & 0,716 & 620 & \\
\hline
\end{tabular}

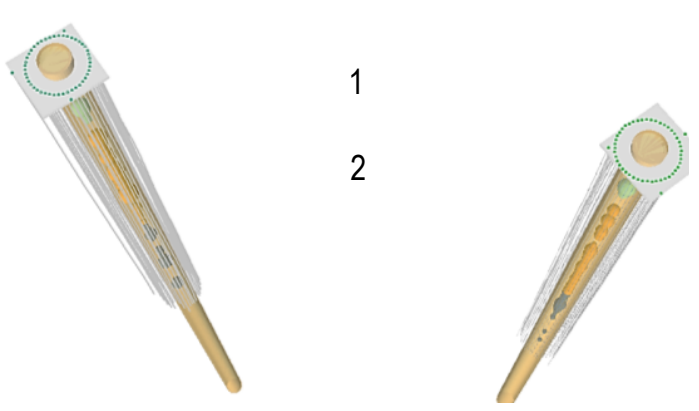

Рис. 5. Стволь иахт, проектируемые в системе ArcGIS: 1 - теплофизические свойства грунта, 2 - расположение замораживающчхх скважин

ния ледопородного массива, кроме этого данная система позволяет выбирать заранее заданные расчетные формулы нестационарной теплопроводности.

Для образования ледопородного ограждения вокруг шахтных стволов (рис. 5) были смоделированы замораживающие скважины по координатам реальных скважин на Талицком участке (рис. $6, a$ ), каждый узел является экспериментальной координатой, определяемой при бурении скважины. На рис. $6, \sigma$ отчетливо видно, что вследствие неоднородности горного массива и других различных факторов бурение скважин происходит не строго вертикально, а форма скважин не является прямолинейной, что необходимо учитывать при расчете времени полного смыкания и обеспечения минимальной толщины ледопородного слоя не ниже предельно допустимого значения при образовании ледопородного ограждения шахтного ствола.

C помощью системы «ArcGIS» можно провести моделирование и наглядно отобразить образование ледопородного массива при использовании различных моделей теплопроводности, включая процесс смыкания ледопородного ограждения вокруг шахтного ствола. На рис. 7 изображено образование ледопородного массива для двух расчетных моделей: замораживание полуограниченной стенки и линейная модель замораживания - при времени 10 и 30 суток на глубине 100 и 120 м.

Фазовым переходом называется переход вещества из одного агрегатного состояния (фазы) в другое. Такие переходы про- 

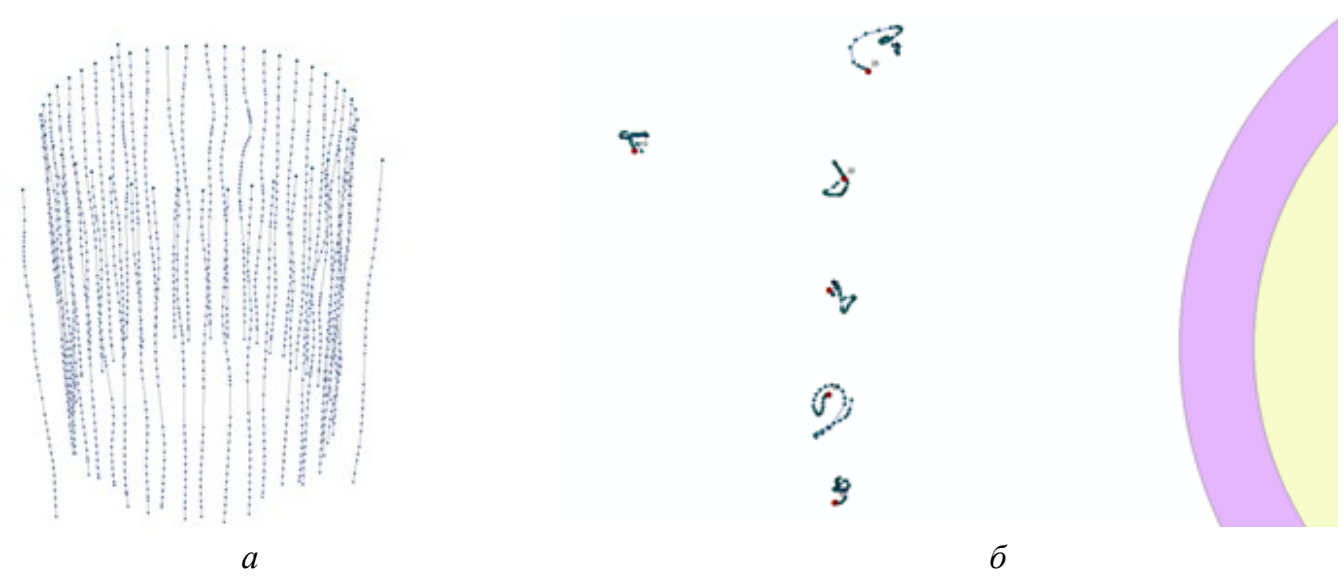

Рис. 6. Расположение замораживающих скважин: $а$-общий вид, б-вид сверху

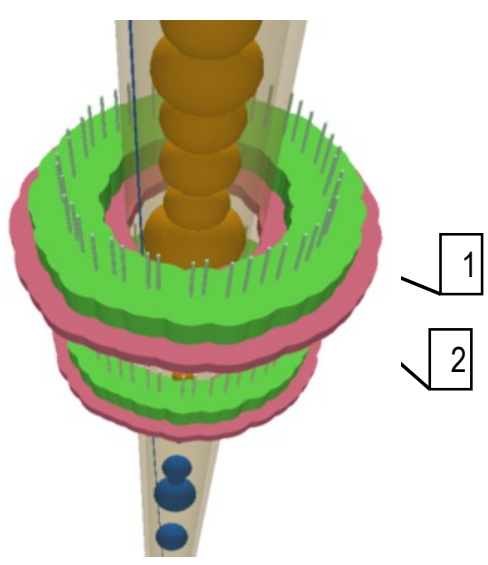

$a$

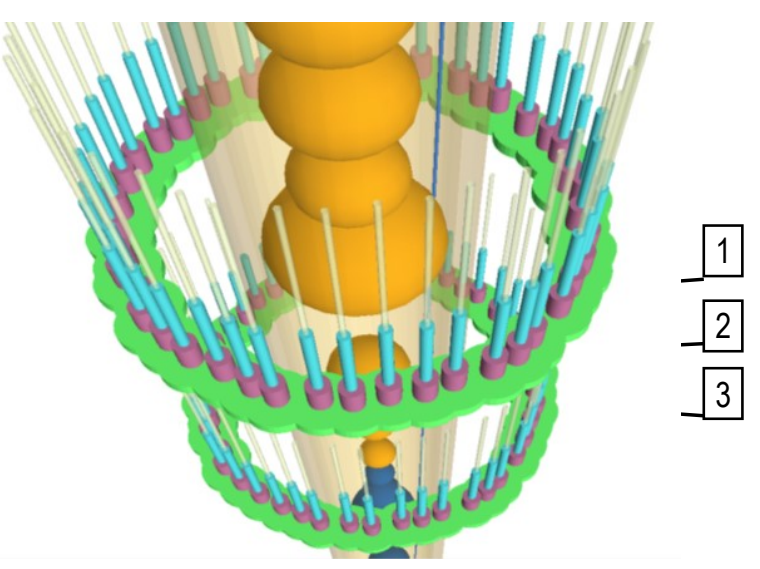

$\sigma$

Рис. 7. Образование ледопородного ограждения вокруг шахтного ствола ( $а$ - полуограниченная стенка; б -линейная модель) при различной продолжстельности замораживания, сут.: 1 - 10, 2 - 30, 3 - 80

исходят при плавлении, затвердевании, парообразовании и т.д. и сопровождаются выделением или поглощением теплоты фазового перехода. Структурным переходом называется преобразование структуры вещества в пределах одной фазы, сопровождающееся выделением или поглощением теплоты структурного перехода [21].

Температура, при которой происходит переход из твердого состояния в твердожидкое (двухфазное), называется температурой солидуса $\left(t_{s}\right)$, переход из двухфазного состояния в жидкое происходит при температуре ликвидуса $\left(t_{1}\right)$. В интервале температур двухфазной зоны $\left(t_{s} \leq t \leq t_{s}\right)$ происходит выделение удельной теплоты фазового перехода $L$, (Дж/кг). При охлаждении поверхности двухфазная зона продвигается, при этом область выделения удельной теплоты фазового перехода заранее неизвестна. Такая задача с подвижной границей фазового перехода называется задачей Стефана.

В соответствии с методом сквозного счета уравнение теплопроводности для всей расчетной области должно содержать источник теплоты фазового перехода только в пределах двухфазной зоны. Это достигается введением функции относительного содержания твердой фазы в элементе объема ( $\psi)$, изменяющейся только в пределах двухфазной зоны, при этом уравнение теплопроводности имеет вид

$$
\rho c \frac{\partial t}{\partial \tau}=\lambda \nabla^{2} t+\rho L \frac{\partial \psi}{\partial \tau}
$$

где $\rho$ - плотность материала, кг/ $\mathrm{m}^{3}$,

$\lambda$ - коэффициент теплопроводности, $\mathrm{BT} /(\mathrm{M} \cdot \mathrm{C})$,

$c$ - удельная теплоемкость, Дж/(кг. $C)$,

$L-$ удельная теплота плавления, Дж/кг.

Функция относительного содержания 
твердой фазы зависит только от температуры, $\psi=1$ при $t<t_{s}, \psi=0$ при $t<t_{l}$ и изменяется $0<\psi<1$ при $t_{s}<t<t_{l}$ отсюда (7):

$$
\frac{\partial \psi}{\partial \tau}=\frac{\partial \psi}{\partial t} \cdot \frac{\partial t}{\partial \tau}
$$

после которой в уравнении теплопроводности (8)

$$
\rho c \frac{\partial t}{\partial \tau}=\lambda \nabla^{2} t+\rho L \frac{\partial \psi}{\partial t} \cdot \frac{\partial t}{\partial \tau}
$$

объединим левую часть и источник тепла

$$
\rho c \frac{\partial t}{\partial \tau}\left(c-L \frac{\partial \psi}{\partial t}\right)=\lambda \nabla^{2} t .
$$

Выражение в скобках является эффективной теплоемкостью:

$$
c_{э ф \phi}(T)=c-L \frac{\partial \psi}{\partial t} .
$$

С введением эффективной теплоемкости уравнение теплопроводности принимает стандартный вид без источника тепла:

$$
\begin{aligned}
& \frac{\partial t}{\partial \tau}=a_{\text {эфф }} \nabla^{2} t \quad \text { при } \quad x \in(0, l), \tau>0, \\
& \left.t\right|_{\tau=0}=\varphi_{1}(r), \\
& \left.\frac{\partial t}{\partial \tau}\right|_{r=l}=0 \\
& \left.t\right|_{r=0}=\mu_{2}(\tau),
\end{aligned}
$$

где: $a_{\phi \phi}-$ коэффициент эффективной температуропроводности $a_{э \phi \phi}=\frac{\lambda}{\rho c_{э \phi \phi}}$.

Если принять линейный закон выделения твердой фазы в двухфазной зоне, то функция $\psi$ и ее производная принимают вид:

$$
\begin{gathered}
\psi=\left\{\begin{array}{ccc}
0 & \text { при } & t>t_{l}, \\
\frac{t_{l}-t}{t_{l}-t_{s}} & \text { при } & t_{s} \leq t \leq t_{l}, \\
1 & \text { при } & t>t_{s} .
\end{array}\right. \\
\frac{d \psi}{d t}=\left\{\begin{array}{ccc}
0 & \text { при } & t>t_{l}, t<t_{s}, \\
\frac{1}{t_{l}-t_{s}} & \text { при } & t_{s} \leq t \leq t_{l} .
\end{array}\right.
\end{gathered}
$$

Эффективная теплоемкость

в этих условиях скачком возрастает в интервале температур двухфазной зоны (рис. 8),

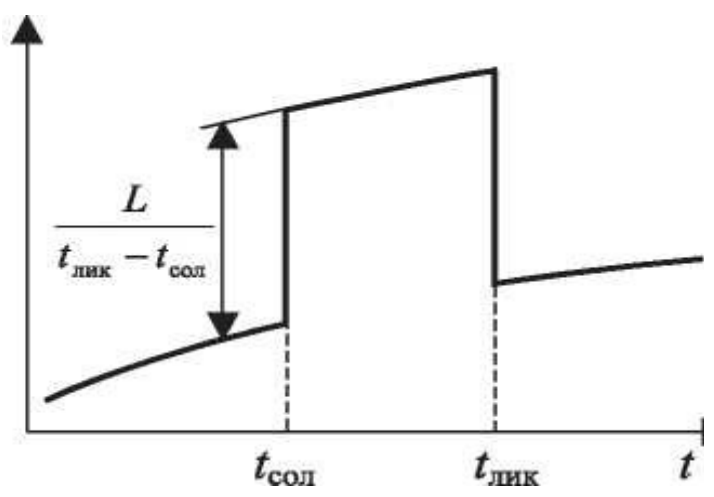

Рис. 8. Вид функции эффективной теплоемкости

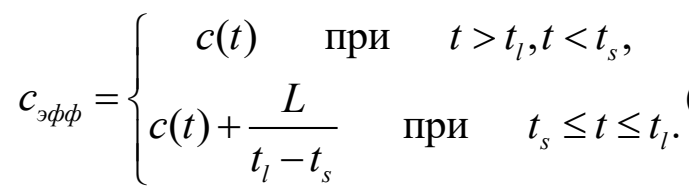

Таким образом, выделение скрытой теплоты затвердевания учитывается за счет эквивалентного повышения теплоемкости в двухфазной зоне. При такой постановке задачи границами двухфазной зоны являются изотермы ликвидуса и солидуса.

Практическое использование ANSYS как инструмента для решения численных методов может быть реализовано на высокопроизводительных вычислительных машинах для обеспечения более точного и относительно быстрого получения требуемых результатов.

В силу того, что структура горного массива по всей глубине является достаточно сложной и при изъятии кернов часть измеряемых свойств, зачастую бывает искажена, использование экспериментальных показаний в расчетных моделях дает ошибку. Так как на реальный объект воздействуют различные факторы, которые, возможно, не были учтены при расчете, было проведено 4 итерационных расчета по определению свойств массива в разные промежутки времени по всей глубине.

Учитывая экспериментальные данные по распространению температур во времени, был произведен перерасчет свойств горного массива, и дана оценка точности расчетов, учитывая внешний диаметр ледопородного колодца в качестве критерия оценки.

Поскольку решение задачи является итерационным процессом, было решено 
пренебречь объемной моделью и использовать плоскую расчетную модель для глубин ствола с шагом 5 м. В ходе решения задачи была создана квадратная пластина с точечными источниками холода, расположенными по координатам реально существующих замораживающих скважин дня каждой из глубин. Свойства горного массива также изменялись в зависимости от исследуемой глубины.

Для расчета создана конечно-элементная сетка, состоящая из 4245 узлов и 4150 элементов, приложены краевые условия в виде начальной температуры тела и постоянной температуры «замораживающих» узлов, равной $-38^{0} \mathrm{C}$. Поверхности тела без краевых условий по умолчанию являются адиабатическими (рис. 9).

Распространение температуры от источника холода изображено на рис. 10 , с помощью графика можно определять толщину ледопородного колодца при заданной температуре кристаллизации.

Далее была создана двумерная конечно-элементная модель нестационарной теплопроводности с фазовым переходом. Для того, чтобы реализовать фазовый переход в численной модели, свойства массива задавались с помощью изменения энтальпии [14]

$$
\Delta H=\int_{T_{0}}^{t} \rho c(T) d T,
$$

где $T_{0}, t$-начальное и текущее значение температуры;

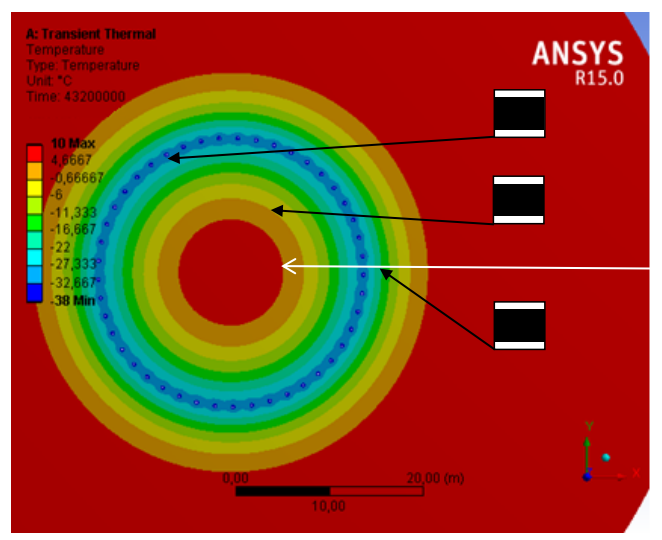

Рис. 9. Поле температуры при воздействии источников холода: 1 - положение замораживающей скважины; 2 - температурный фронт, 3 - радиус расчетной области

\section{$\rho$ - плотность грунта, кг $/ \mathrm{m}^{3}$;}

$c(T)$ - удельная теплоемкость, Дж/(кг $\left.{ }^{\circ} \mathrm{C}\right)$, которая определялась с помощью выражения (17):

$$
c_{\text {эфф }}=\left\{\begin{array}{c}
c(t) \quad \text { при } \quad t>t_{l}, t<t_{s}, \\
c(t)+\frac{L W}{t_{l}-t_{s}} \quad \text { при } \quad t_{s} \leq t \leq t_{l} .
\end{array}\right.
$$

где $W$ - суммарная влажность грунта, доли единицы.

Используя упрощенную постановку задачи, где удельная теплоемкость жидкой и твердой фаз является постоянной, были найдены узловые точки на диаграмме зависимости энтальпии от температуры (рис. 11).

В процессе итераций были допущены осреднение свойств и определение диаметров внешнего ледопородного массива на основе этих вычислений, т.к. с увеличением времени достижение математической моделью экспериментального внешнего диаметра сопутствовало резкому уменьшению температуропроводности.

В результате проведенных численных расчетов (рис. 12) выявлено, что на глубинах более 150 м математическая модель совпадает с экспериментальными данными, погрешность не превышает $10 \%$, тогда как в верхней части ствола расхождения в показателях достигают значений выше $20 \%$, что говорит о несовершенстве математической модели, т.к. она не учитывает влияния соседних слоев друг на друга в процессе заморозки.

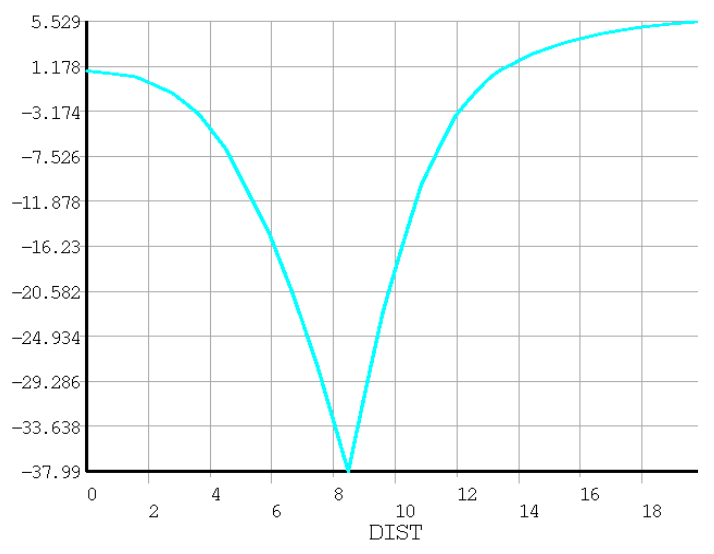

Рис. 10. Распределение температуры от центра ствола к границе расчетной области 


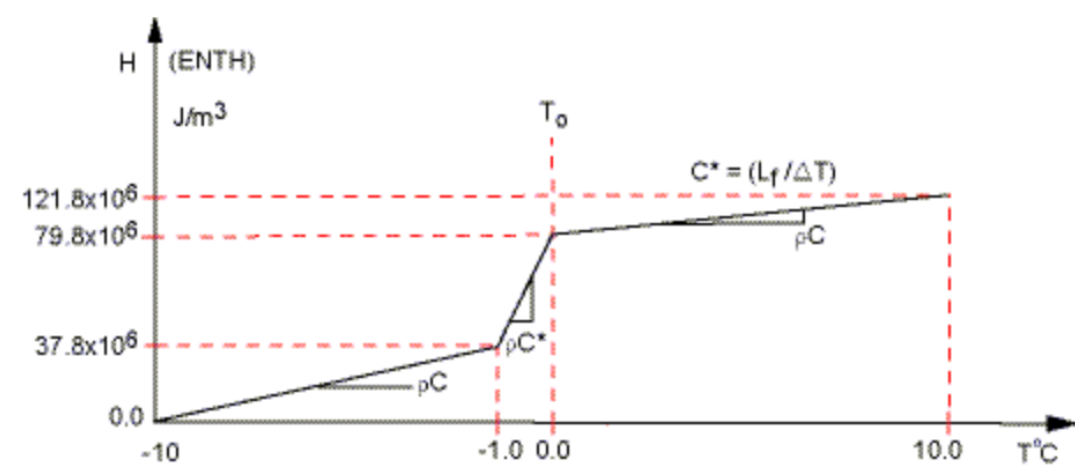

$a$

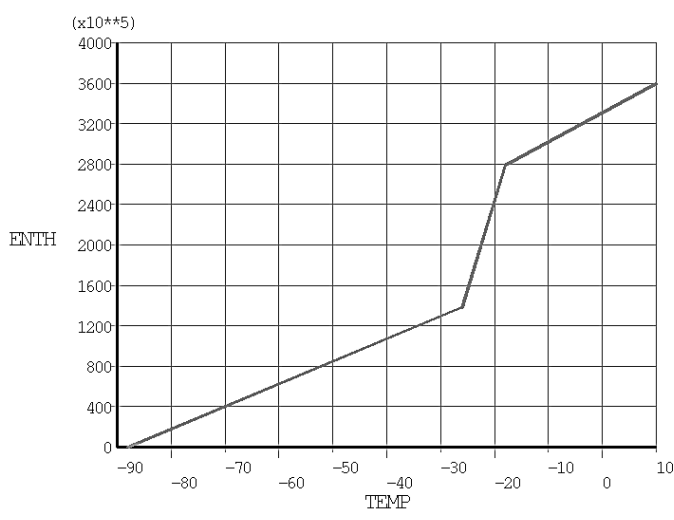

$\sigma$

Рис. 11. График зависимости энтальпии от температуры: а-схема в ANSYS Help; б - для расчета горного массива на глубине 180 м

Так, на рис. 12 изображено изменение отношения внешнего расчетного диаметра $d_{\text {sol }}$, м к расчетному $d_{\text {exp }}$, м - по всей глубине шахтного ствола $L$, м - во времени.

В работе представлено решение задачи нестационарной теплопроводности бесконечного цилиндра с граничными условиями первого рода при помощи двух методов: аналитического и метода конечных элементов. Для моделирования динамики температурного поля вокруг шахтного ствола в процессе заморозки был использован прикладной пакет ANSYS V.15 WORKBENCH.

Получены зависимости толщины ледопородного массива от времени и начальной температуры среды без учета фазового превращения. Определены приблизительные сроки образования ледопродного массива требуемой толщины, необходимого для проходки шахтного ствола.

Моделирование сложных объектов наукоемкий процесс, поэтому результаты, полученные в ходе выполнения работы, не

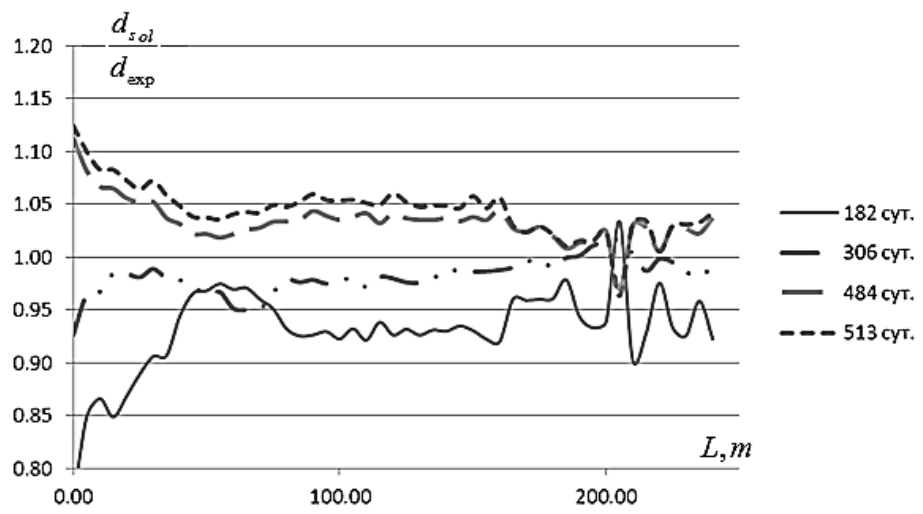

Рис. 12. Зависимость точности вычислений от глубины слоя 
являются точными, т.к. не были учтены все возможные негативные факторы, влияющие на ледообразование в горных породах.

Структура горного массива представляет собой сложный композиционный материал, поэтому для решения задачи образования ледопородного массива необходимо использование механики деформирования и разрушения композиционных материалов. В дальнейшем планируется решить данную задачу как с точки зрения теплофизики, так и механики композиционных материалов для более точного и качественного анализа процесса ледообразования.

\section{Библиографический список}

1. Аверин Б.В. Общая схема решений краевой задачи нестационарной теплопроводности с внутренними источниками теплоты для многослойных конструкций // Вестник Самарского технического университета. Серия: Физ.-Мат. Науки. - 2009. - № 2(19). - С. 274-277.

2. Агишева Д.К., Шаповалов В.М. Инженерный анализ нестационарной теплопроводности многослойной пластины // Известия ТГТУ. - 2002. - Т.8. - С. 612-617.

3. Венгеров И.Р. Теплофизика шахт и рудников. Математические модели. Том 1. Анализ парадигмы. Донецк: Норд-Пресс, 2008. - 632 с.

4. Инженерный анализ в ANSYS Workbench: Учеб. пособ. / В.А. Бруяка, В.Г. Фокин, Е.А. Солдусова [и др.]. - Самара: СамГТУ, 2010. - 271 с.

5. Капустин C.A. Метод взвешенных невязок решения задача механики деформируемых тел и теплопроводности: Учеб. пособие. - Нижний Новгород: Нижегородский госуниверситет, 2010. - 60 с.

6. Карташов Э.М. Интегральные соотношения для аналитических решений обобщенного уравнения нестационарной теплопроводности // Вестник МИТХТ. - 2011. - Т. 6 - №3. - С. 106-110.

7. Конечно-элементное моделирование задач геомеханики и геофизики / Власов А.Н., ВолковБогородский Д.Б., Заментский В.В. [и др.] // Вестник МГСУ. - 2012. - №2. - С. 52-65.

8. Коновалов В.И., Пахомов А.Н., Гатапова Н.Ц., Колиух А.Н. Методы решения задач тепломассопереноса. Теплопроводность и диффузия в неподвижной среде: Учеб. пособие. Тамбов: Изд-во Тамб. Гос. техн. Ун-та, 2005. - $80 \mathrm{c}$.

9. Константинова С.А., Хронусов В.В. К оценке региональных напряжений в верхней части земной коры Урала и Волго-Камского геоблока в рамках модели блочного массива // Физико-технические проблемы разработки полезных ископаемых.- 1998. - №5. - С. 60-70.

10. Константинова С.А., Хронусов В.В. Проявление горного давления вокруг подземных выработок в калийных рудниках в случае негидростатического начального напряженного состояния // Физикотехнические проблемы разработки полезных ископаемых. - 1999. - №2. - С. 25-34.

11. Кузнецов Г.В., Шермет М.А. Разностные методы решения задач теплопроводности: Учеб. пособие. Томск: Изд-во ТПУ, 2007. - 172 с.

12. Марданов Р.Ф. Численные методы решения плоской задачи теплопроводности: Учебнометодическое пособие. - Казань: Изд-во Казанского гос. ун-та, 2007. - 23 с.

13. Матяшов Д.М., Губеладзе О.А. Определение температурного поля в двухслойном толстостенном цилиндре конечных размеров при действии источника тепла простойной мощности // Известия ЮФУ. Технических науки. Тематический выпуск «Компьютерные и информационные технологии в науке, инженерии и управлении». -2008. - № 11 (88). - С. 25-29.

14. Миляев. А.С. Альтернативная методика расчета промерзания слоистых оснований сезонных зимних лесовозных дорог // resour. Technol. - 2010. - № 8. - C. 83-87.

15. Немировский Ю.В., Янковский А.П. Численное интегрирование двумерных краевых задач с большими градиентами решения // Вычислительные технологии. - 2000. - Т. 5. - №4.- С. 82-96.

16. Румянцев A.B. Метод конечных элементов в задачах теплопроводности: Учеб. пособ. Калининград: Калинингр. ун-т, 1995. - 170 с.

17. Тихонов А.Н., Самарский А.А. Уравнения математической физики: Учеб. пособие. 6-е изд., испр. и доп. - М.: Изд-во МГУ, 1999. - 798 с.

18. Усманов С.Ф. Современное программное обеспечение для решения задач геомеханики // Вестник КРСУ. - 2008. - Т. 8. - № 1. - С. 81-84.

19. Федюкин В.А. Проходка стволов шахт способом замораживания. - М.: Недра, 1968. -350 с.

20. Фокин В.М., Бойков Г.П., Видин Ю.В. Основы технической теплофизики: Монография. - М.: Машиностроение-1, 2004. - 172 с.

21. Цаплин А.И. Теплофизика в металлургии: учеб. пособие. - Пермь: Изд-вл Перм. гос. техн. ун-та, 2008. $-230 \mathrm{c}$.

22. Чупров И.Ф., Канева Е.А. Уравнения параболического типа и некоторые методы их решения: Учеб. пособ. - Ухта: УГТУ, 2012. - 103 с. 
23. Шестаков В.Н., Шестаков А.Н. Методы теории теплопроводности в транспортном строительстве: учеб. пособ. - Омск: СибАДИ, 2011. - 72 с.

\title{
MATHEMATICAL MODELING OF FROZEN ROCK MASSIFS TEMPERATURE FIELDS CONSIDERING PHASE TRANSITIONS DURING THE SHAFT DEEPENING
}

\author{
A.A. Chekalkin, R.N. Suleimanov \\ Perm National Research Polytechnic University
}

The object of the research is the formation of frozen rock massif during the shaft deepening. The purpose of the work is to create a mathematical model of the rock mass dimensional temperature fields in the process of freezing wells during the mine shaft penetration. This work was carried out at the Perm National Research Polytechnic University. Design calculations provided by the customer, analytical solution of the unsteady heat conduction equation to determine the preliminary calculation of time of the frozen rock massif formation were done. ANSYS application package was used to simulate the dynamics of the temperature field in this work, with which it is also possible to determine the ice formation time in the rock massif. The initial geometrical and thermophysical information was prepared in the geographic information system «ArcGIS». Dependences frozen rock massif thickness on time and the initial temperature of the environment are obtained. The approximate dates for the formation the required thickness of the frozen rock massif, which are required for the shaft deepening, are determined.

Keywords: frozen rock massif, thermal conductivity, heat capacity, well, shaft, mathematical modeling, unsteady thermal conductivity.

\section{Сведения об авторах}

Сулейманов Руслан Нафисович, аспирант, Пермский национальный исследовательский политехнический университет (ПНИПУ), 614990, г. Пермь, Комсомольский пр., 29; e-mail: SuleimanovRN@gmail.com

Чекалкин Андрей Алексеевич, доктор физико-математических наук, профессор, ПНИПУ; e-mail: a.a.chekalkin@yandex.ru 